\title{
In Memoriam: Richard V. Kadison (1925-2018)
}

\section{Liming Ge, Arthur Jaffe, Marc Rieffel, and Mikael Rørdam}

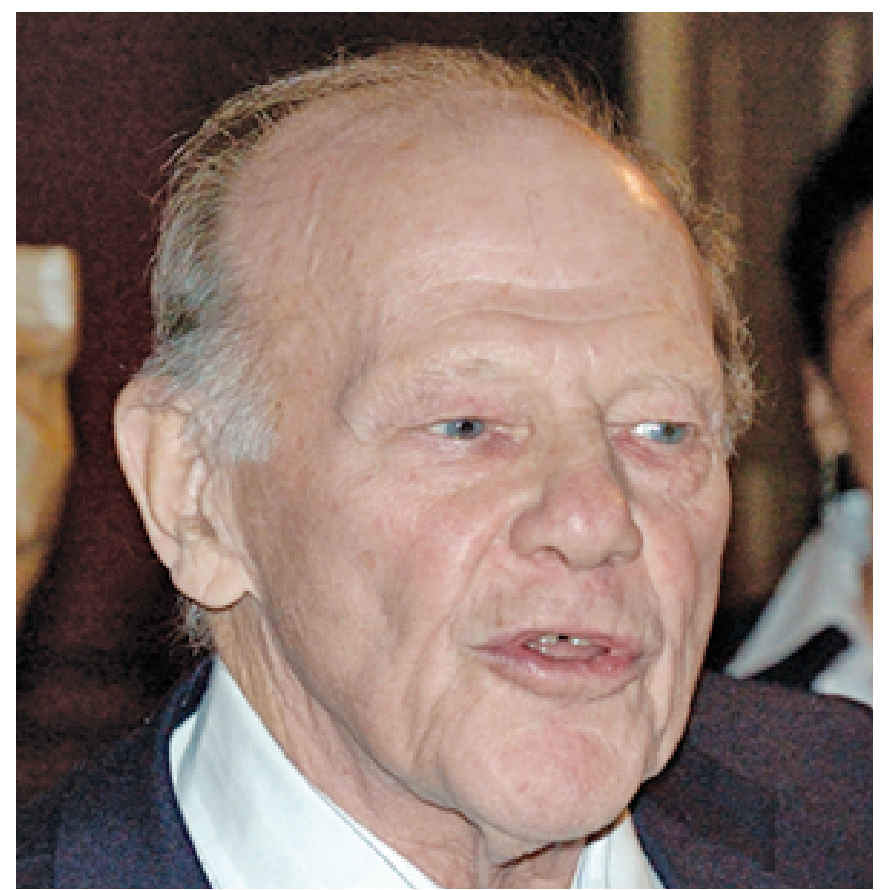

Figure 1. RichardV. Kadison (1925-2018).

Liming Ge is a professor at the Chinese Academy of Sciences and the University of New Hampshire. His email address is 1 iming@unh. edu.

Arthur Jaffe is Landon T. Clay Professor of Mathematics and Theoretical Science at Harvard University. His email address is jaffe@g . harvard. edu. Marc Rieffel is a professor at the University of California, Berkeley. His email address is rieffe1@berke1 ey. edu.

Mikael Rørdam is a professor at the University of Copenhagen. His email address is rordam@math.ku.dk.

Communicated by Notices associate editor Stephan Ramon Garcia.

For permission to reprint this article, please contact: reprint-permission aams.org.

DOI: https://dx.doi.org/10.1090/noti 1949
Richard V. Kadison, "Dick" among friends and colleagues, died on August 22, 2018. Mathematicians regard Dick as the "dean" of operator algebra theory. Beginning in the 1950s, he almost single-handedly carried the torch for the subject, and he remained one of its foremost leaders during the following decades. He nurtured the field by making deep scientific contributions and by attracting younger mathematicians, whom he energetically supported. The subject of operator algebras grew out of the 1920s ferment involving representation theory for compact groups, the theory of linear operators on Hilbert spaces, and their use in the formulations of quantum mechanics by Heisenberg and Schrödinger. This led John von Neumann, with his coauthor Francis J. Murray, to write a series of deep and highly influential papers about a broad class of algebras of operators on Hilbert spaces, now known as von Neumann algebras. Out of the wartime Soviet Union, a remarkable paper by I. Gelfand and M. Naimark emerged in 1943 in which they developed the theory of a larger class of algebras of operators on Hilbert spaces, now called $C^{*}$-algebras. The von Neumann algebras may be thought of as noncommutative measure spaces, while $\mathrm{C}^{*}$-algebras may be viewed as noncommutative topological spaces, an analogy arising from the classification of the commutative algebras.

Dick was born in 1925 in New York, where he attended the famous Bronx High School of Science, a public school with admission based on competition. After graduation in 1942, he studied at the City College of New York. During WWII he transferred to the Merchant Marine Academy and went from there to the Merchant Marine as an officer, where he served on several vessels, making missions to Europe and the Pacific. Returning from the war, Dick began graduate school at the University of Chicago, and in 1950 he completed his PhD thesis, "A Unified Theory for Topological Algebras," under the supervision of Marshall Stone. 
The following year, at the Institute for Advanced Study, Dick met the Danish mathematician Bent Fuglede. They wrote a paper on what is now called the Fuglede-Kadison determinant, a widely used invariant for operators in type $\mathrm{II}_{1}$ von Neumann algebras. Their collaboration marked the beginning of Dick's close bond with Denmark and Norway. The present popularity of operator algebras in these countries can be directly traced to Dick's influence.

In 1952 Dick became an assistant professor at Columbia University. He received an Alfred P. Sloan research fellowship in 1958 and was promoted to professor in 1960. In 1954-55 he travelled to Copenhagen on a Fulbright fellowship to continue his collaboration with Fuglede. There he met Karen Holm, and they married on June 5, 1956. They have one son, Lars, who is an active mathematician.

During the 1950s Dick wrote several deep and groundbreaking papers. Some of the directions that he launched in these papers concern the order properties of $\mathrm{C}^{*}$-algebras, related order-unit spaces, the properties of the group of isometries of $\mathrm{C}^{*}$-algebras, positive maps between $\mathrm{C}^{*}$-algebras, the transitivity of irreducible representations of $\mathrm{C}^{*}$-algebras (the famous Kadison transitivity theorem), and the linear groups in von Neumann algebras.

With I. Singer, he introduced another important notion: triangular operator algebras. In their 1959 paper they also explored a problem whose origin dates back to Dirac, namely, the extension of pure states. They showed that pure states on the continuous diagonal of the bounded operators on the Hilbert space $H=L^{2}([0,1])$ can have multiple extensions to pure states on the bounded operators on $H$. They went on to ask if any pure state on the discrete diagonal of the bounded operators on a Hilbert space extends uniquely to a (pure) state on all bounded operators. Over the next decades, this question was shown to be equivalent to several other important questions, including ones in frame theory, engineering, computer science, and linear algebra. It became widely known as the Kadison-Singer problem. The problem was settled, affirmatively, in 2013 by A. Marcus, D. Spielman, and N. Srivastava using methods from theoretical computer science.

During his years at Columbia, Dick supervised a string of students, including Richard Lashof (1954), James Glimm (1959), Marc Rieffel (1963), and Erling Størmer (1963). Over his entire career, Dick advised a total of twenty-two doctoral students, including, besides Rieffel, two other coauthors of this article, Mikael Rørdam (1987) and Liming Ge (1995). Many of Dick's students became influential mathematicians themselves.

The mathematics department at the University of Pennsylvania, with the assistance of Provost David Goddard, went to great lengths to recruit Dick from Columbia. They finally succeeded in 1964, and as part of the package, Goddard gave up his own Gustave C. Kuemmerle Professorship, a position that Dick kept for the rest of his life. Dick was effective in obtaining government grants to support his many doctoral students and also visits by many young promising mathematicians who had begun working in the field. He successfully built a strong group in operator algebras, which included six leading experts as members of the senior faculty. Practically overnight, the University of Pennsylvania became the world center for research in operator algebras.

During the 1960s the theory of operator algebras began to have strong connections to various specific aspects of quantum physics, and Dick held the leadership in developing these connections. He explored the types of von Neumann algebras that come out of quantum field theory, the perturbation theory of von Neumann algebras, as well as dynamics in the setting of $\mathrm{C}^{*}$-algebras, asymptotically abelian systems, nets of $\mathrm{C}^{*}$-algebras, and derivations of von Neumann algebras, forging lasting ties with S. Doplicher, R. Haag, D. Kastler, J. Roberts, and D. Robinson. In 1967 Dick also organized the first major conference on operator algebras. This Baton Rouge conference played a central role in increasing the momentum of research in this field; importantly, it served as "midwife" in the birth of Tomita-Takesaki theory. In that meeting, Tomita distributed his hand-written manuscript, which Takesaki developed further at Penn over the next couple of years. This breakthrough enabled Araki's work on relative entropy and Connes' groundbreaking work on classification of factors. Its impact persists today both in physics and in mathematics.

During the 1970s, in addition to actively continuing his earlier explorations, most notably on the connections between mathematics and quantum physics, Dick was a leader in developing a deep cohomology theory for von Neumann algebras. Dick organized a large, three-week conference on operator algebras in 1980 in Kingston, Ontario. One can imagine a "Woodstock festival of operator algebras," featuring remarkable progress: the Connes classification of injective von Neumann algebras and his new theory of noncommutative geometry, the Brown-Douglas-Fillmore theory of extensions of $\mathrm{C}^{*}$-algebras and K-homology, completely positive approximation and nuclearity, and the emerging classification of $\mathrm{C}^{*}$-algebras. This meeting played a major role in solidifying the interrelations between operator algebra theory and the rest of mathematics.

Dick continued making many personal contributions to the theory of operator algebras. He initiated the similarity question: Is any bounded (not necessarily ${ }^{*}$-preserving) representation of a $\mathrm{C}^{*}$-algebra on a Hilbert space similar to a ${ }^{*}$-homomorphism? While this question remains open, it was later shown by U. Haagerup that the answer is yes for all cyclic representations. The corresponding similarity question for groups is conjectured to hold precisely for amenable groups. This is known as the Dixmier Unitarizabil- 
ity Conjecture and holds for all amenable groups and fails for groups containing a nonabelian free group.

During the 1970s and 1980s Dick worked frequently with his collaborator John Ringrose on Fundamentals of the Theory of Operator Algebras. This became an inviting, four-volume textbook that remains a major resource both for students and established researchers. With L. Ge, Dick proved a beautiful rigidity theorem for tensor products of von Neumann algebras, showing that the only intermediate von Neumann algebras between $\mathbb{C} \otimes M$ and $N \otimes M$, where $M$ is a factor and $N$ is any von Neumann algebra, are the obvious ones: $N_{0} \otimes M$, where $N_{0}$ is a von Neumann subalgebra of $N$.

During the last decade of his life, Dick developed a theory for certain algebras of unbounded operators affiliated with von Neumann algebras, which he called Murray-von Neumann algebras. His most recent paper on the topic, joint with A. Thom and former student Z. Liu, is awaiting publication. Dick's last doctoral student, S. Nayak, received his PhD in 2016.

Dick was a gifted writer with a wonderful sense of humor. Among Dick's publications one finds a substantial number of expository articles and portraits of fellow mathematicians. The tribute he wrote about his friend and collaborator, Is Singer, was entitled "Which Singer is that?". One can almost hear Dick pronouncing the question, precisely mimicking the person who asked it. The 28-page-long article is a lovely blend of mathematics and anecdotes.

Dick received the Steele Prize for Lifetime Achievement from the American Mathematical Society in 1999; he was a member of the inaugural class of AMS Fellows; he was a member of the US National Academy of Sciences and served for several years as chair of the mathematics section. Dick received honorary doctoral degrees from the Université

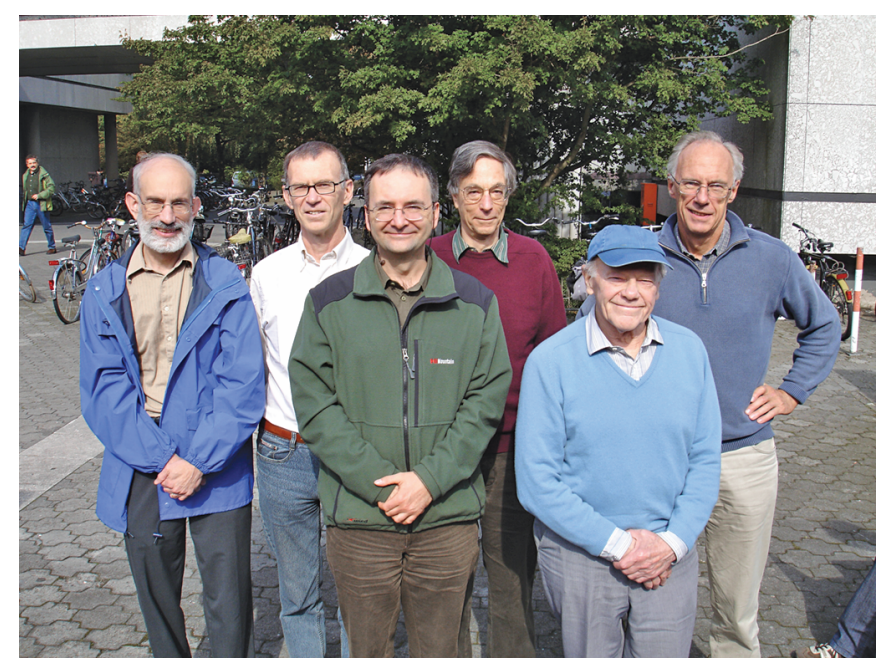

Figure 2. Dick Kadison at the 60th birthday conference for Joachim Cuntz in 2008 with two of his mathematical children, Marc Rieffel and Erling Størmer (behind Dick), and (from the left) three of his mathematical grandchildren, Jonathan Rosenberg, Jean Renault, and Piotr Hajac.
Aix-Marseille and the University of Copenhagen. He was a Foreign Member of the Royal Danish Academy of Sciences and Letters and of the Norwegian Academy of Science and Letters. In 2018 Dick was elected Fellow of the American Academy of Arts and Sciences.

On a completely different note, Dick was an accomplished gymnast, a genius with flying rings, and a member of the US team headed for the 1952 Olympics in Helsinki, from which, however, he had to withdraw at the last moment because of a tendon injury. He understood the value of physical strength and also, at times, the value of being a mathematician incognito. When his gymnastics friends asked him about his profession he would reply that he writes papers. When asked what kind of papers, he would say "technical papers" in a convincing, dismissive, but still amiable way that was his signature.

When Dick died at the age of ninety-three following a short illness, he had been teaching in the spring semester and had plans for teaching the following semester. He had a long-lasting influence on the many people he had contact with over his life, both mathematically and personally, and took great pride in this.

\section{Masamichi Takesaki ${ }^{1}$}

The news of Dick's passing away saddened me very much and brought deep emptiness as well as loneliness to me, ending fifty-one years of our friendship. We met for the first time at the famous international conference on operator algebras at LSU, Baton Rouge, in the spring of 1967 . I knew his work, however, long before this meeting. Indeed, his work on the transitivity of an irreducible $\mathrm{C}^{*}$-algebra played a dominant role in my decision to become an operator algebraist in 1957. It was reviewed in the AMS Math Reviews by J. Feldman as follows: "The author proves the startling fact that if a $\mathrm{C}^{*}$-algebra of operators acting on a Hilbert space has no nontrivial invariant closed linear manifolds, then it has no nontrivial invariant manifolds whatsoever."

I started my graduate study in 1956, when the tidal wave of operator algebras had started to recede. Although I fell in love with operator algebras upon reading von Neumann's double commutant theorem, in the beginning of 1956, at the end of my undergraduate study, it was whispered in Japan that the field of operator algebras was finished. My supervisor didn't like the field of operator algebras either. But Dick's transitivity result, together with Sakai's celebrated characterization of $\mathrm{W}^{*}$-algebras, made me believe that with these incredibly deep results the field of operator algebras couldn't die. It was just going through deep preparation for the next big steps. My conclusion from Dick's result was correct, and the field of operator algebras started to move forward again with strong strides a few years later

${ }^{1}$ Masamichi Takesaki is a professor emeritus at the University of California, Los Angeles. His email address is mt@math.ucla.edu. 


\section{MEMORIAL TRIBUTE}

in the sixties, highlighted by work on the type I C*-algebras of J. Glimm, a student of Dick.

Naturally, I was curious about Dick's philosophy of operator algebras and his school at the University of Pennsylvania. At the Baton Rouge conference in 1967 Dick asked me if I was interested in spending the academic year of 1968-69 at Penn. I immediately accepted his offer. When I asked him about my duties, the answer was, "You have no duties here. Please spend a pleasant year here in Philadelphia." My reaction was "Wow, no duty. What can I do with this free time?"

Very few people believed in Tomita's work that was distributed at the Baton Rouge conference. It was flatly rejected as written very poorly. As I had promised Professor N. H. Hugenholtz, I studied the paper of Tomita carefully and had confirmed the validity of the main claim of Tomita's work by the summer of 1967 . But when I came to Penn a year later, all of Kadison's research group still denied the validity of Tomita's claim. So I had a sharp conflict with them. To resolve it, I was forced to reinvestigate Tomita's work and write up my own account of his claim. The flat rejection by my colleagues at Penn, together with Kadison's invitation to spend a pleasant time there, was the key to the birth of the Tomita-Takesaki theory on noncommutative integration of von Neumann algebras. By the end of 1968 I had completed my notes on Tomita's work, which were received warmly by Dick and others. A careful check-up seminar that ran from January 1969 until the end of April was very successful. Everybody in Kadison's group took part, presented seminar lectures, and finally confirmed the theory: the birth of Tomita-Takesaki theory. A year later the notes were published as Lecture Notes Vol. 128, from Springer Verlag. It is clear to me that without Dick's leadership and generous hospitality, the Tomita-Takesaki theory would not have been developed at that time. We all owe him for this success. I am very grateful for his leadership.

During this exciting period, all of Japan's universities were drowning in deep chaos caused by a derailed student movement, which was caused by government mishandling of student demands. All Japanese research mathematicians were completely exhausted from the campus disorder. The chaos made me rethink my eventual return to my home university, Tohoku University, and I decided to stay out of Japan. When Henry A. Dye recognized my desire to remain in the US, he and the UCLA Department of Mathematics started to solicit letters of recommendation from experts on operator algebras. Kadison's letter played a dominant role in the decision to appoint me as a full professor, a fact I was told years later.

Kadison's list of open problems delivered at the Baton Rouge conference played a very important role in the development of the theory of operator algebras. Many of the problems have been solved by remarkable people: A. Connes, S. Popa, U. Haagerup, G. K. Pedersen, and so

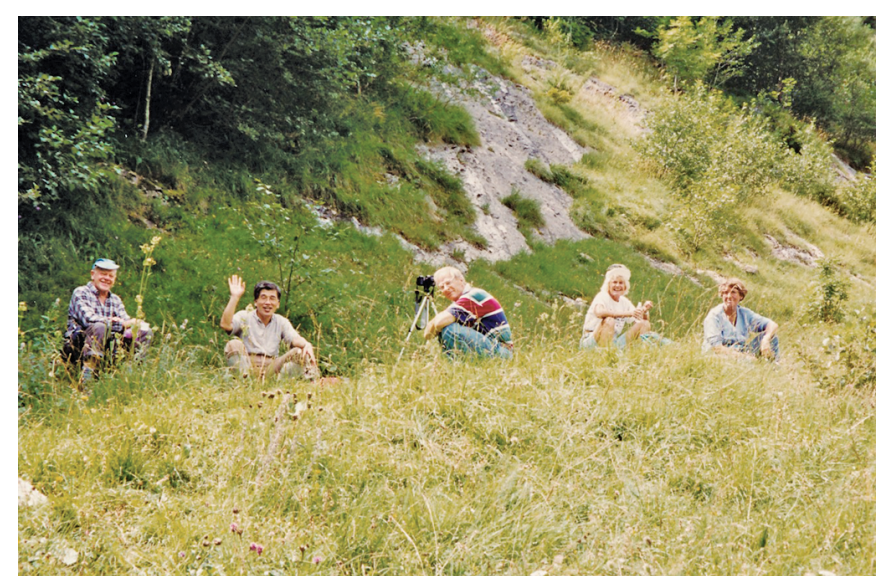

Figure 3. Dick, MasamichiTakesaki, Nico Hugenholtz, Karen Kadison, and Ankie Hugenholtz on a hike in Switzerland in 1994 prior to the ICM in Zürich.

on. With Dick's leadership, the field of operator algebras rebounded from the low-tide years of the late 1950s to the high tide in the mid-1960s and has maintained high visibility ever since.

I had numerous discussions with Dick about the future of operator algebras, which benefitted me immensely. I'll miss Dick badly. I pray here for the peaceful rest of Dick's soul.

\section{Sorin Popa ${ }^{2}$}

I first met Dick Kadison in the summer of 1980 on the occasion of an AMS Summer School in operator algebras. This was a meeting of large proportions, with more than two hundred participants, intended to present the state of the art of the subject. The program took place at Queens University in Kingston, Canada, and involved three weeks of intense activities, from July 10 to August 5, with tens and tens of lectures and presentations. It was almost single-handedly organized by Dick Kadison, who dedicated a tremendous amount of time and energy to putting together an event of such magnitude. I can say without hesitation that it was, to this day, the most extraordinary and stimulating mathematical event I have ever been part of.

Just before that meeting, Kadison invited several of us to Philadelphia to visit the math department at Penn for a week. Dick was a living legend in operator algebras, with many classic contributions in just about any area of the subject. Last-minute issues with the Summer School were certainly keeping him very busy, but despite this, he took a lot of his time to talk mathematics with me, a young novice in his twenties. I keep a vivid memory of him commenting on his well-known 1967 Baton Rouge List of Problems. This has never been published but was widely circulated in the operator algebras community, five pages in old typing style with about twenty problems/questions stated "without

\footnotetext{
${ }^{2}$ Sorin Popa is a professor at the University of California, Los Angeles. His email address is popa@math.ucla.edu.
} 
an attempt to establish sources" or "discuss their origin." Dick took the problems one by one, explaining to me their background, history, and motivation, details on who authored each problem, and the progress that had been made on each one of them. This included the famous free group factor problem, originating from Murray and von Neumann's seminal 1943 paper "Rings of operators III," which asks whether the $\mathrm{II}_{1}$ factors $\mathrm{L}\left(\mathrm{F}_{\mathbf{n}}\right)$ associated with the free groups with $n=2,3, \ldots$ generators are mutually isomorphic or not (the problem is still open to this day). That discussion with Dick Kadison, followed by the Summer School in Kingston and the great mathematical encounters and discussions I was able to have there, had a huge impact on my research in the forthcoming years.

During the few days in Philadelphia, Dick and Karen Kadison treated us with immense attention and care. I was at their house for dinner every evening, together with other colleagues from around the world who stopped like me at Penn en route to Kingston. It was there that I first met Masamichi Takesaki and Ed Effros, who were to become my colleagues at UCLA seven years later. The lively discussions at these parties were an occasion to discover how sharp and funny Dick could be on just about any subject. The dinners would always take place in the Kadisons' beautiful garden. Karen was very proud of the garden and all things related to it. She and Dick had installed a high pole with a place on top for feeding birds, and they both complained bitterly about a squirrel who was constantly stealing the bird food. Dick explained how he would try all kinds of tricks to keep this from happening and how the squirrel would just outsmart him every time, finding her way to the food: "This squirrel is amazingly smart," he said, then added with a thoughtful look: "If I could just put up there the free group factors, then I am sure she would figure it out in no time!"

I have fond memories of all my encounters with Dick over the years. I cherish all that time. I somehow always thought this would go on forever. In a way, it certainly will, through his mathematical legacy and our collective memory.

\section{Joachim Cuntz ${ }^{3}$}

With Dick, one of the fixed stars in the sky of operator algebras has passed away. Through his work, and also through his personality, he has had a tremendous influence.

I met him for the first time when I was still a student, just finishing my $\mathrm{PhD}$. It was during the special year on quantum field theory and operator algebras at Bielefeld in 1975. I had managed to solve a problem of Dick's good friend John Ringrose and had asked him for an appointment. When he came to the meeting, he was just a few minutes

\footnotetext{
${ }^{3}$ Joachim Cuntz is a professor at WWU Münster. His email address is cuntz@uni-muenster.de.
}

late, but he apologized profusely for that (remember that I was just a student and he was one of the leaders in the field). A few days later he invited me to dinner in a good restaurant, together with some very established senior colleagues. In this way he swiftly introduced me to the inner circles of the field of operator algebras.

A few years later I received an offer for a tenured associate professorship at the University of Pennsylvania. That offer came at a time when there were basically no tenured positions available at German universities at all. I am still grateful to Dick and his colleagues for that opportunity. At that time the group at the University of Pennsylvania was considered to be the Mecca of operator algebras. When I arrived with my family at Philadelphia, Dick helped us in all possible ways: for instance, with cars-fixing old used cars was one of his specialties. We quickly became really good friends. He invited me regularly for lunch at the Faculty Club, where we had long and deep discussions. His favorite topic was of course the field of operator algebras with its past, present, and future, but he liked to discuss all kinds of things. On each topic he had very definite opinions, which were very well thought through and which he would support with arguments based on a very detailed analysis. One of his singularities was the very long parentheses in the course of his explanations-sometimes even parentheses within parentheses. But eventually after each parenthesis, however long, he would always return to the original subject at exactly the point where he had left it. Of course, we also discussed mathematics and in particular operator algebras, where he had a remarkable intuition. When confronted with a question he often referred to his "gut feeling," and I must say it was always correct.

The atmosphere in the operator algebra group at Penn was pleasant and friendly, not least due to Dick. There was one particular institution: the one buck lunch. Once every week Dick invited all members of the group from student

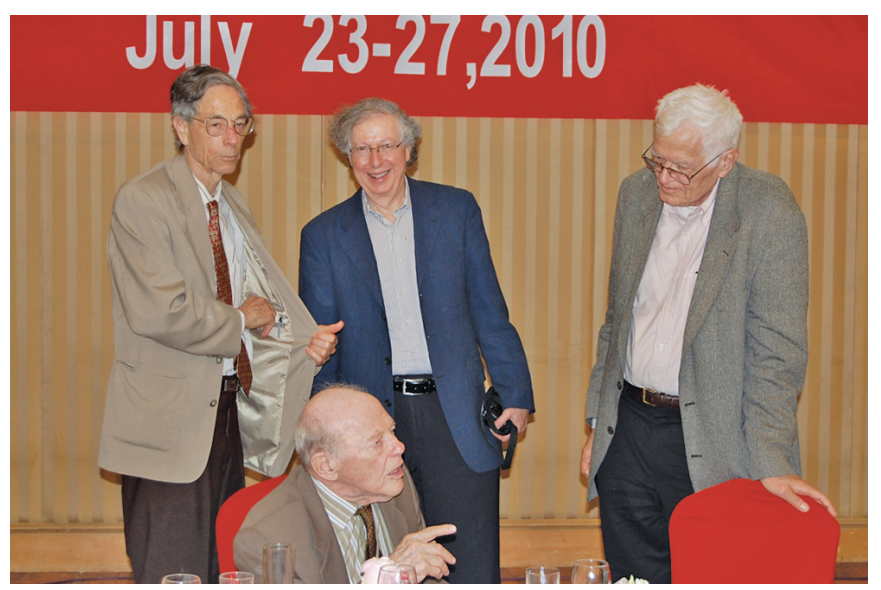

Figure 4. Marc Rieffel, Arthur Jaffe, and James Glimm standing behind Dick at an AMSS conference Operator Algebras and Applications - In Celebration of 80Years of Operator Algebras, Beijing, 2010. 
to professor to lunch in the Faculty Club. Everybody had to pay a symbolic dollar and then had a free lunch at Dick's expense. My wife and I also have fond memories of Dick's wife, Karen, and of the other members of the group, in particular of Bob Powers and his family.

Dick saw it as his mission to keep the field of operator algebras alive, and when it had started to make tremendous advances in the mid-seventies, to further advance and support it. A culmination of that effort was the great three-week conference at Kingston in 1980. It is still very instructive nowadays to have a look at the proceedings of that conference, which contain much of the coming developments in embryo.

Dick enjoyed teaching a lot and saw it as a great privilege that he did not have to retire. He remained active very long, not only in teaching but also in contributing substantial ideas to his field up to the end.

\section{Sergio Doplicher ${ }^{4}$}

The sad news about Dick found me totally unprepared, feeling that an impressive empty space had suddenly opened itself both in the landscape of math and in that of my closest friends. I will dwell here mostly on the second aspect, since the first, I'm sure, is so evident and will be so well described by the words of others.

One month or so after having received my Laurea in Rome I moved to IHES to spend a semester there, attracted by an exceptional gathering of long-term visitors, notably Arthur Wightman, Harry Lehmann, and Hans Borchers, the Olympus of what was then called "axiomatic quantum field theory." But its variant in terms of operator algebras, pioneered by Haag, Kastler, and Araki, had already caught my interest, so when Arthur once told me at tea, "Dick Kadison will visit here this coming spring 1964," it sounded like the announcement that the second peak of Parnassus would move to us.

To my delighted surprise the expected visitor was not a distant immortal but an extremely friendly person, always eager to share his immense knowledge with young beginners like me. We then kept meeting often in the subsequent years, again in IHES, and then in Bandol at Daniel Kastler's residence, a sort of Summer Palace not far from the Luminy campus of the Universite Aix-Marseille. Here I had the immense pleasure of collaborating with Kadison and Kastler on Asymptotically Abelian Systems and of hearing Is Singer, attracted by Dick, present the Index Theorem before the paper itself appeared in print.

A few years later, also attracted by Dick, a young star passed by Bandol, explaining some spectacular mathematics to Dick, Daniel, and me while we were having tea in Daniel's residence. Dick was slowing him down to a more

\footnotetext{
${ }^{4}$ Sergio Doplicher is a professor emeritus at the Sapienza University. His email address is dop1iche@mat. uni roma1.it.
}

human speed, translating each sentence in what he called "crystal clear" terms; it was a new classification of type III factors. Of course, I am talking of Alain Connes.

These are just a few examples of how Dick was not only a shining star radiating his science but also attracting many celestial objects with his presence. I am proud to say that we became good friends over the years. From Princeton, where I spent a semester in 1967, I used to visit him in Philadelphia, enjoying the warm hospitality of Dick and his delightful wife, Karen. I also met their son, Lars, at that time a young boy who was posing intelligent questions from time to time.

Besides mathematics, I remember that Dick liked to spread pieces of knowledge useful for common life or to explain American expressions (like "I put a foot in my mouth," later appearing in the title of a book by Saul Bellow!) or even detailed stories about colleagues as insights into their human character. Some stories were short and memorable. For example, Irving Segal joining him and Is Singer at a coffee table, and when the waiter came along asking what he wanted to drink, after an oblique glance to the half-empty cups on the table, answering, "If that's a coffee I want a tea; if that's a tea I want a coffee!" And the one about the physicist bravely confronting somebody he thought had stolen his watch on a street one night in New York but discovering, back at the hotel, that now he had a watch too many!

Dick was also a master of style in collaborations. I learned from him many things that remained with me for life, both concerning general ethics in science as well as practical "ways and means." One example: any partial piece of knowledge a collaborator acquires should be "written up" (not just "written down," he insisted) and made available to the coworkers as an "intelligence unit." We adopted this style also in later collaborations with Daniel, Rudolf Haag, and John Roberts.

In the incredibly active scientific life of Dick, over so many decades, he had exchanges with many scientists. Dick was my only friend who had exchanged "Hallo!" with Einstein at IAS in Princeton and who could remember his long detailed discussions with John von Neumann on operator algebras-discussions that, Dick said, although von Neumann had already left the subject at that point, made it evident that operator algebras had remained the topic closest to his heart. Dick had discussions on open problems about von Neumann algebras with Murray (von Neumann's coauthor of the famous series of papers "On rings of operators"), who would say from time to time, "But Johnny thinks that..."

Dick's deep mathematical insight was accompanied by an everlasting contagious enthusiasm for mathematics and especially for the theory of operator algebras, which he so significantly shaped and masterfully presented in his books 
with John Ringrose. His lectures were always shining with clarity, really "crystal clear."

I had the honour to talk at a couple of meetings in China to honour Dick on his birthday. With the help of some colleagues, I prepared a slide in Chinese characters, saying "Dick Kadison, wan wan suyn!", i.e., "one hundred millions years!", a wish of long life that, I was told, was actually used in old times but only for the emperor. But I could add that Dick was the emperor of $\mathrm{C}^{*}$-algebras. And as such he will remain forever in our hearts as a bright star in the subject and at the same time as an ever helpful dear friend.

\section{Edward G. Effros ${ }^{5}$}

Quantum variables provided some of the most startling development in the mathematics and physics of the last century. Owing to the discoveries of such researchers as Schrödinger, Heisenberg, and Dirac, it was soon realized that one had to model physical variables with Hilbert space operators rather than with functions as in the classical theory. This, in turn, led to the development of "noncommutative" or operator analysis by mathematicians including von Neumann, Gelfand, Kadison, Singer, and Takesaki.

Kadison soon became one of the leading figures in this exciting endeavor due to his complete mastery of the classical and quantum theories. His success with collaborations with American colleagues (e.g., Singer) was due to his inexhaustible energy and his brilliant insights.

Kadison was also in large part responsible for the establishment of this subject in other locations such as Scandinavia, France, and Japan. It is a pity that he is gone and thus does not have a chance to witness the future impact of his fundamental contributions to mathematics.

On a personal note, Rita and I were the beneficiaries of the amazing hospitality of Karen and Dick during our time at Penn. Their home was the scene of countless math

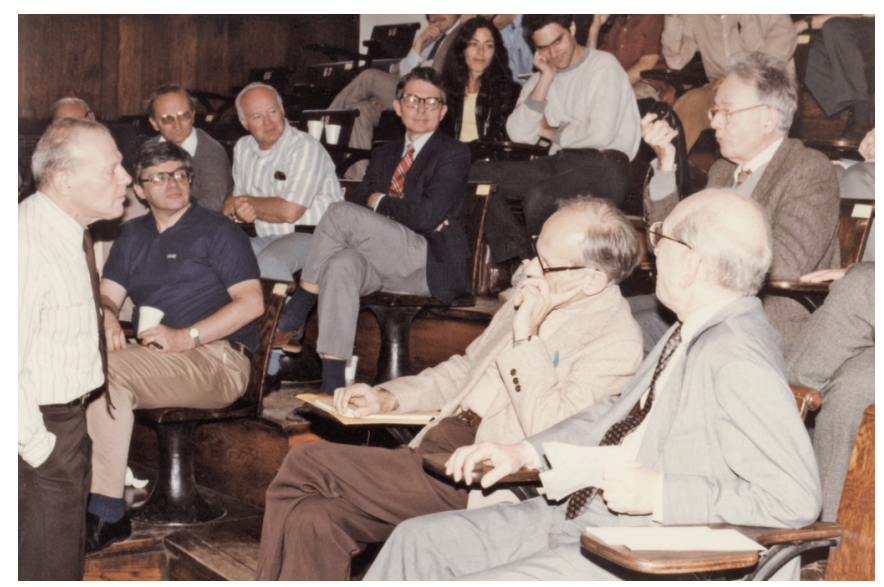

Figure 5. Dick Kadison in discussion with George Mackey at a 1982 conference for ArthurWightman in Princeton.

\footnotetext{
${ }^{5}$ Edward G. Effros is a professor emeritus at the University of California, Los Angeles. His email address is ege@math.ucla.edu.
}

parties, not to mention the amazing Danish brunches, enhanced by an endless supply of Aquavit.

\section{James Glimm ${ }^{6}$}

\section{In Gratitude}

I would like to express my gratitude for all that I have learned from Dick, both professionally and personally. I start with the professional dimension. I regarded the thesis problem Dick suggested to me as a narrow technical exercise. I profoundly misjudged the quality of his proposal. It formed the technical basis for two major contributions to the theory of operator algebras. The first was a noncommutative generalization of the Stone-Weierstrass theorem on the sufficiency of pure states. In the classical (commutative) case, the pure states are closed in the set of all states, so the closure question does not arise. The noncommutative case and the added closure hypothesis came from Dick. The importance of the closure is that it turned out to be larger than was generally expected. From the thesis construction it was possible to show a key result on the large reach of the closure of the pure states. The second major theorem was the structure of type I $\mathrm{C}^{*}$-algebras. These are a kind of opposite extreme, and the thesis construction was used to show the equivalence of various type I characterizations.

At a personal level, I am grateful that Dick never questioned my leaving the subject of $\mathrm{C}^{*}$-algebras. He supported the ups and downs of my efforts to make a mark in new areas.

More broadly, I learned important lessons in scientific character from Dick. I learned the highest levels of scientific integrity his career represented and the search for truth and meaningful scientific structure his career embodied. I

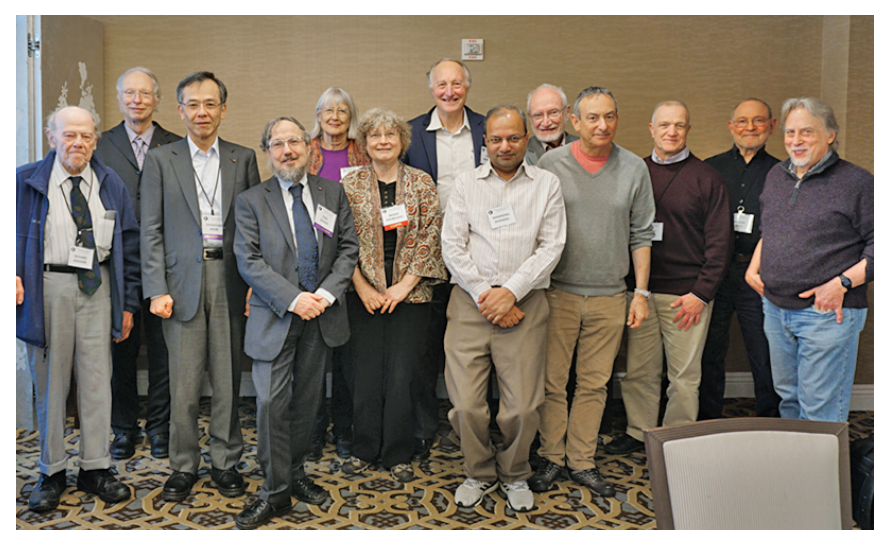

Figure 6. A meeting of the math section of the US National Academy of Sciences, April 30, 2018. From left: Dick, Harold Stark, Shigefumi Mori, Don Zagier, Dusa McDuff, Ingrid Daubechies, John Morgan, Manindra Agrawal, William Browder, Kenneth Ribet, Robert Bryant, Hyman Bass, and Jeff Cheeger.

\footnotetext{
${ }^{6}$ James Glimm is a distinguished professor at Stony Brook University. His email address is g7imm@ams. sunysb.edu.
} 
learned from him my first lessons of science as a cultural activity, dependent on human interactions.

I am, and will always be, profoundly grateful to Dick.

\section{Robert Powers ${ }^{7}$}

I came to Penn in 1967 because of Dick Kadison. He had put together one of the best groups in the world in functional analysis, consisting of Ed Effros, Michael Fell, Lajos Pukansky, Shoichiro Sakai, and David Shale, and what made it even more exciting was the constant stream of visitors. Tuesday was our seminar day and many of us met for lunch at the Faculty Club. Dick and his wife, Karen, hosted numerous parties and dinners at their house, and, of course, there were numerous gatherings at restaurants after a seminar or colloquium or after graduate students passed their final thesis defense. I remember one dinner at the Peking Palace when Baruch Solel, who had just finished his thesis under Dick, got the fortune "You will go to a land of sunshine," to which Dick replied, "You'll get that job in Israel!" Besides being one of the finest Chinese restaurants, their fortune cookies were remarkably prophetic.

With Dick as the head of the operator algebra group, it was very much like a family, and we saw each other outside the seminar room more often than inside, and this applied to the visitors as well. Most years we had at least one long-term senior visitor and one or two people who visited for a week or so, and of course there were people who came to give talks or colloquiums. There were numerous young people: one, two, or three a year. I counted ten people I collaborated with whom I first interacted with while they were at Penn. Two people I want to single out are Masamichi Takasaki, who did his groundbreaking work on the Tomita-Takasaki theory, and Vaughan Jones, who discovered the Jones index of subfactors and his famous knot polynomial while at Penn.

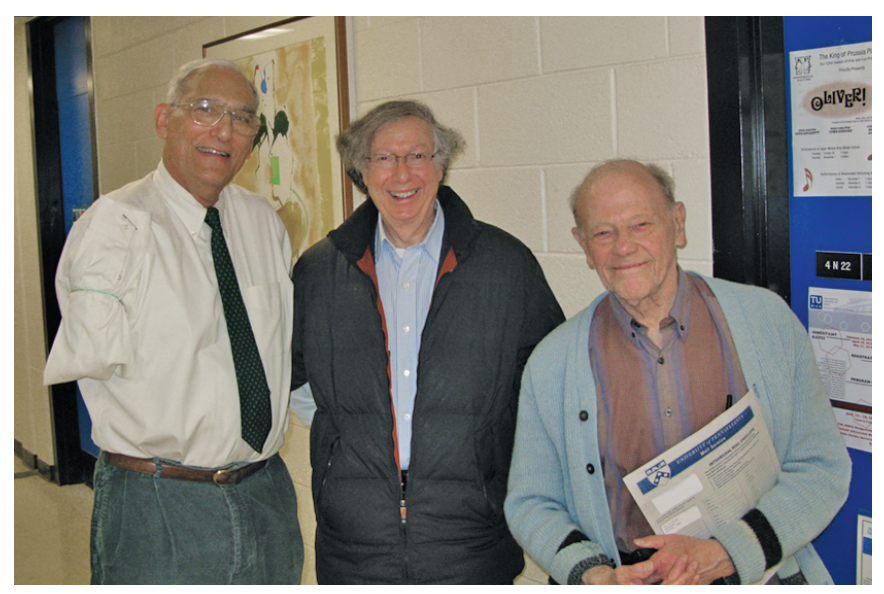

Figure 7. Stephen Schatz, Arthur Jaffe, and Dick Kadison at Penn, 2010.

\footnotetext{
${ }^{7}$ Robert T. Powers is a professor emeritus at the University of Pennsylvania. His email address is rpowers@math. upenn. edu.
}

Being a member of Dick's group at Penn has had an enormous influence on my career. To relay all of the dinners, parties, and conversations would take a book the size of War and Peace.

\section{Isadore Singer ${ }^{8}$}

I first met Dick in Chicago in 1947 after serving in the army for three years during WWII. My interest at the time was mostly in physics and literature. An army officer's experience gave me strength in identifying talents. Soon I discovered an outstanding group of mathematicians at the University of Chicago. Dick was among the elite of superstars. Our collaboration extended much beyond our student days. I was most impressed by his carefulness and learned to be that way. Somehow I learned a great deal from him but never reached his level of carefulness in mathematics.

My mathematics career started in the area of operator algebras, which was not a popular subject. (One evening I was beaten up by mobsters in Chicago while walking downtown and picking a vector in my head. My ability in mathematics improved greatly after the incident.) Dick and I graduated at the same time in Chicago. He went to Princeton, and I took an instructor position at MIT. We visited each other often and worked on the same topics. When in Princeton, we often made appointments to meet and talk to Johnny (von Neumann), who gave us many insights in the development of operator algebras. More significant research collaboration with Dick started in the mid-1950s after I took an assistant professor position at MIT. I had no teaching duties for the first five years. I often stayed with Dick at Columbia University in New York, and he also spent a year at MIT. We worked together day and night and often took breaks by going to jazz clubs after midnight. I wrote four joint papers with Dick during that period, including the one where we asked the pure state extension problem, known as the Kadison-Singer problem. I left the subject in the early 1960s as everyone else did. But Dick remained loyal to the subject and dedicated his whole life to it. Without Dick, the subject of operator algebras might not have existed.

We remained close till the moment he passed away. I will miss him dearly.

\section{Erling Størmer ${ }^{9}$}

Next to my parents, Dick is the person who has had the most influence on my life. It started when I was a graduate student at Columbia University in the years around 1960. In the spring of that year, before I was going home to Nor-

\footnotetext{
${ }^{8}$ Isadore Singer is a professor emeritus at the Massachusetts Institute of Technology.

${ }^{9}$ Erling Størmer is a professor emeritus at the University of Oslo. His email address is er1ings@math.uio.no.
} 
way for the summer, I approached him and asked about a possible thesis project. "Read chapters 1 and 3 in Dixmier's book on von Neumann algebras," he said. So I did and came back to him in the fall with a shallow understanding of the subject. "What did you like most?" he asked, and I answered, "The order structure." That was a lucky choice, because Dick was the person who introduced the theory of positive linear maps on $\mathrm{C}^{*}$-algebras in the early $1950 \mathrm{~s}$ with, among other things, his famous Schwarz inequality. So I started on the subject with Dick as my thesis advisor.

In the 1950s very few people worked in operator algebras, and mathematicians knew very little about the subject. But in the 1960s the subject exploded. Physicists doing quantum statistics and field theory entered the area. Dick was their main contact in $\mathrm{C}^{*}$-algebras, and through him I got to know some of the top people working in the subject. One of them, Daniel Kastler, was a good friend of Dick and worked in Marseille but lived in the beautiful town Bandol, on the coast east of Marseille. I spent much delightful time in Bandol working with Kastler and my new friends Derek Robinson and Sergio Doplicher.

I spent much time in other places too because of Dick. In the academic year 1965-66 he was one of the organizers of a year specializing on $\mathrm{C}^{*}$-algebras at Aarhus University in Denmark. I spent the whole year there taking part in the activities, learning a lot, and building new friendships. Gert K. Pedersen, for example, quite often came on his motorcycle from Copenhagen.

I had the pleasure of spending much time in Philadelphia. Being in Philadelphia as Dick's guest, the year when Takesaki corrected and rewrote Tomita's manuscript, I had the great experience of following the process and reading Takesaki's manuscript as it developed. In Philadelphia I got to know Dick and his wife, Karen, better and to enjoy their hospitality, and I learned through long lunches at the Faculty Club about all aspects of the field, not only technical ones but also its history, standards, ethics, personalities, and more.

If we also consider Dick's mathematical contributions it becomes clear that he was the central and dominant person in operator algebras for many years. For me personally, my mathematical life would have been totally different if it hadn't been for Dick. I am extremely grateful for what he did.

\section{Erik Christensen ${ }^{10}$}

There is a joke among Danish mathematicians asking, Which Danish person has had the biggest impact on modern Danish mathematics? The answer is Karen Kadison. The reason why Dick and Karen got married is Bent Fuglede. Dick and Bent were both guests at the Institute for Advanced Study

\footnotetext{
${ }^{10}$ Erik Christensen is a professor emeritus at the University of Copenhagen His email address is echris@math.ku.dk.
}

in Princeton in the year 1950-51. Dick had just finished his PhD, and Bent had just proven the famous Fuglede's theorem, and they both had an interest in operators and operator algebras. In Princeton, they extended the theory of determinants from matrices to rings of operators, a result that is still in use. Invited by Bent, Dick came to Copenhagen in 1953 and was installed in a boardinghouse where Karen Holm also stayed. With the establishment of family ties to Denmark, Dick and Karen have visited the country many, many times, with probably more than ten visits lasting between a month and a year, where Dick has stayed and worked either in Aarhus, Odense, or Copenhagen. The most important visit with respect to the development of the groups of operator algebraists in Denmark was organized at Aarhus University in the academic year 1965-66, where S. Bundgaard was creating a new mathematics department at Denmark's new second university. Kadison brought several students and young collaborators along, amongst which were Jim Glimm, Ed Effros, and Erling Størmer. Bent Fuglede had supervised Esben T. Kehlet on operator algebras in Copenhagen, and Esben later had several students in this area of mathematics. The most famous of these students is the late Gert K. Pedersen. Both Gert and Esben went to Aarhus during the year 1965-66, and many contacts between Danes and the international top researchers in this field were established in this way. Gert Pedersen supervised, amongst many others, the giant in mathematics, the late Uffe Haagerup. Altogether, at least seventeen Danish and four foreign researchers working on operator algebras have been appointed as professors by Danish universities, and many more have obtained a $\mathrm{PhD}$ degree in this subject in Denmark. At least five Danes have obtained their PhD in mathematics from the University of Pennsylvania, and three of these with Dick as their supervisor.

Karen and Dick's son, Lars, who is also a mathematician, had a position in Denmark for some time and now lives in Norway. He kept his apartment in Denmark, close

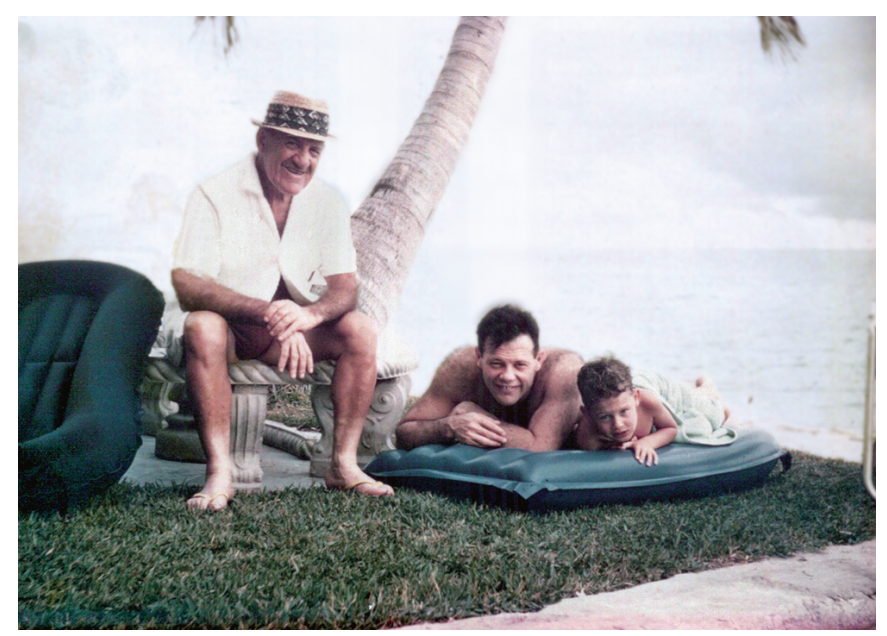

Figure 8.Three generations of Kadisons: David, Dick, and Lars (from 1962). 


\section{MEMORIAL TRIBUTE}

to Copenhagen, so in the later years Karen and Dick first visited Lars in Norway, then they went to the family cottage on the small island of Fur in Denmark, and finally they stayed some days in Lars' apartment. This made it possible for Dick to visit the institutes in Oslo, Aarhus, Odense, and Copenhagen nearly every summer. His last visit was in the summer of 2017.

The connection to Norway goes back to Columbia University in 1956, where Erling Størmer from Oslo was an undergraduate student. He met Dick in a class on logic, unaware of Dick's link to Scandinavia. Erling got his PhD degree from Columbia University with Dick as supervisor. A group was established in Oslo with many students in operator algebras, including the late Ola Bratteli. Of those, three got their PhD from the University of Pennsylvania.

\section{Lars Kadison ${ }^{11}$}

My dad, grandfather D.K (or Dave), and I were all born in New York City, about thirty years apart starting in 1895. D.K and Dick both did non-combat military service at the tail end of a world war, as a navy sergeant swimming instructor and a merchant marine lieutenant, respectively. D.K went to college at Columbia (with a degree in pharmacy), but my dad placed out of most of the college years and left early for graduate school. This he regretted somewhat, missing the opportunity for a liberal arts education. I think he would have enjoyed taking classical music appreciation classes, a literature course on German short fiction, perhaps ancient history as I did at Princeton. My dabbles in literature led him to discover and appreciate Hermann Hesse's The Glass Bead Game, David Lodge's academic novels, and conversely, I read the book he loved about Japan, The Chrysanthemum and the Sword.

My dad added a runner-up trophy to the family collection in golf, chess, and gymnastics, in this case almost going to the Summer Olympics in 1948 and 1952. As a by-product of his gymnastics, begun in his early teens, he was extremely strong. He had many dinner party stories to tell about his days on board a ship or on the streets of New York or Chicago. He told me once, perhaps in one of our weekly telephone conversations since I left home in 1976, that his technique with a large, aggressive man was to go towards him covering his head from the blows, and once he grabbed his torso, he would overpower him. (Perhaps moments before, an accompanying mathematician friend of his would say, "No, Dick, no!") Later he mellowed and admitted that studying law would have been more useful.

Like the other Kadisons, my dad was attracted to foreign women. He traveled to Denmark through his mathematical bromance with Bent Fuglede and met my mom in the mid-1950s. He learned Danish, a difficult language with

\footnotetext{
${ }^{11}$ Lars Kadison is Dick Kadison's son. His email address is 1kadison amath.upenn.edu.
}

twenty-five vowel sounds, two of which exchanged lead to howls of laughter from the natives. An only child, Dick was absorbed into my mother's large family in Viborg and became the cake provider, the one who bought many small cakes at Marie Christensen's Konditori for savoring at the family tea at three. He spent at least five sabbatical years in Denmark. At one time, he took an evening class in auto repair, practicing on his own 1958 Volvo, a course he loved, which gave him the feeling for many years that there was nothing about his old cars he could not fix, given enough time with the right equipment and auto parts.

My dad had a lifelong interest in dining at restaurants, occasionally a Michelin-starred place. He ate very slowly while telling stories, eventually eating huge amounts, but never gaining weight. He would invite as many as he could think of and would tip very well as a rule. His pet peeve would be when I went along in my fifties and the young Italian waiter would hand me the check.

My dad fought retirement as others would fight to stay alive. He did not have a hobby, a paradise, or a research obsession suitable for his retirement (unlike his father, who enjoyed golf tremendously and had discovered South Florida for the family). He continued twenty or twenty-five years beyond a normal retirement age and received a paycheck the same month of his passing. He died in a sense the way he would have liked, "with his boots on." I will miss him a lot.

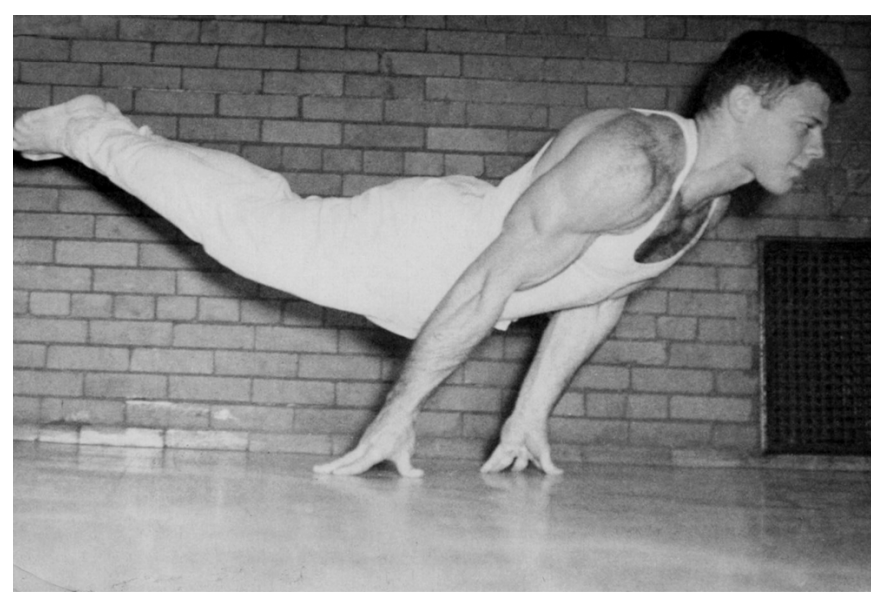

Figure 9. Dick Kadison was an accomplished gymnast.

\section{Selected papers and books by Kadison:}

Fuglede B, Kadison RV, Determinant theory in finite factors, Ann. of Math. (2) 55 (1952), 520-530. MR0052696

Kadison RV, Singer IM, Extensions of pure states, Amer. J. Math. 81 (1959), 383-400. MR0123922

Kadison RV, Derivations of operator algebras, Ann. of Math. (2) 83 (1966), 280-293. MR0193527

Doplicher S, Kadison RV, Kastler D, Robinson DW, Asymptotically abelian systems. Comm. Math. Phys. 6 (1967), 101-120. MR0216299 


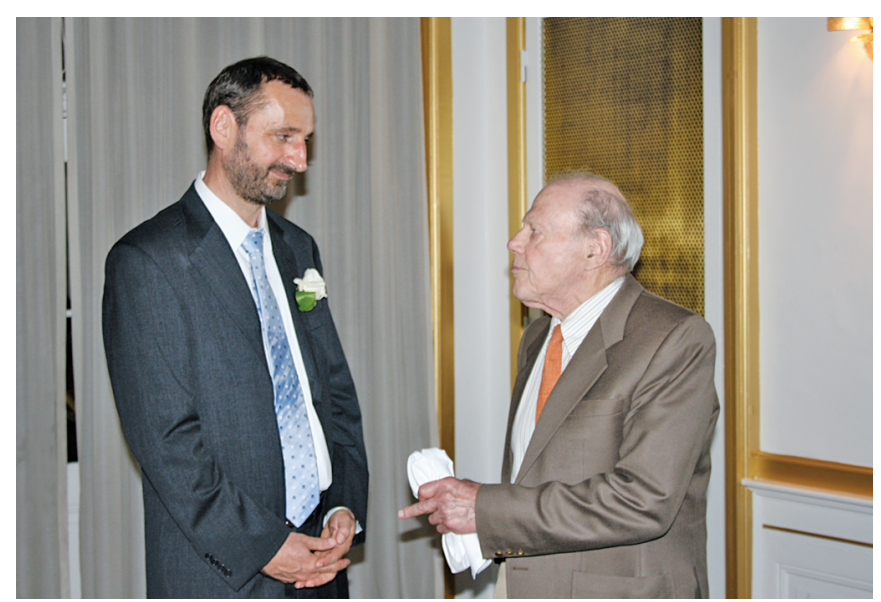

Figure 10. Mikael Rørdam (former student) and Dick, 2009.

Kadison RV, Ringrose JR, Cohomology of operator algebras, I. Type I von Neumann algebras. Acta Math. 126 (1971), 227-243. MR0283578

Kadison RV, Kastler D, Perturbation of von Neumann algebras, I. Stability of type. Amer. J. Math. 94 (1972), 38-54. MR0296713

Kadison RV, Similarity of operator algebras. Acta Math. 141 (1978), no. 3-4, 147-163. MR0491546

Kadison RV, Ringrose JR, Fundamentals of the theory of operator algebras, Vol. I. Elementary Theory. Pure and Applied Mathematics 100. Academic Press, Inc. New York, 1983. MR0719020

Kadison RV, Ringrose JR, Fundamentals of the theory of operator algebras, Vol. II. Advanced Theory. Pure and Applied Mathematics 100. Academic Press, Inc. Orlando FL, 1986. MR0859186

Ge L, Kadison RV, On tensor products for von Neumann algebras. Invent. Math. 123 (1996), no. 3, 453-466. MR1383957

Kadison RV, Zhe L, Derivations of Murray-von Neumann algebras. Math. Scand. 115 (2014), no. 2, 206-228. MR3291726

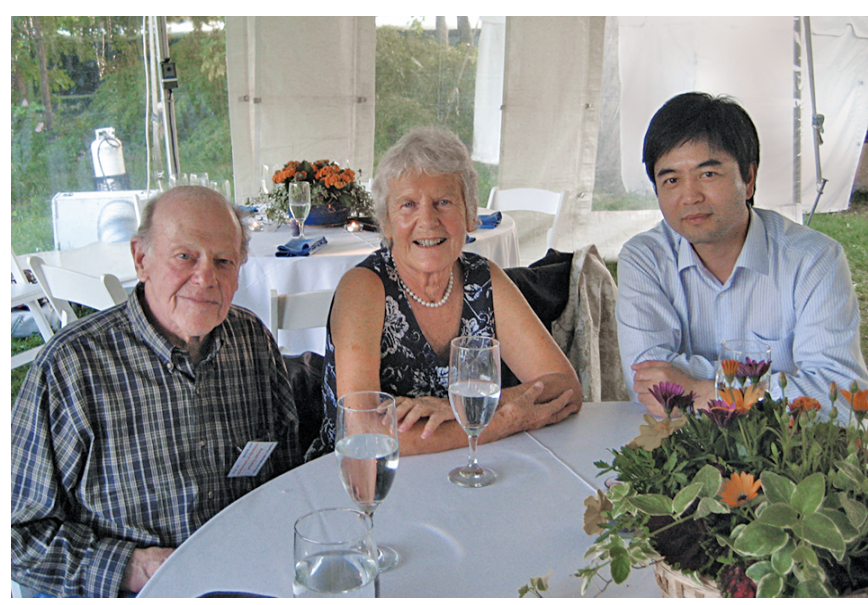

Figure 11. Dick, Karen, and Liming Ge (former student) at a garden party at ls Singer's home on the occasion of his 85th birthday, 2009.

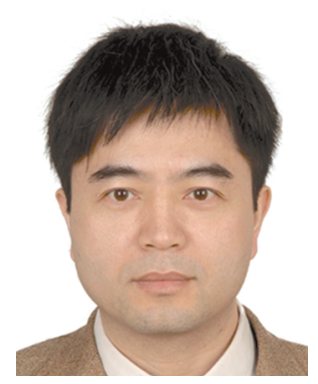

Liming Ge

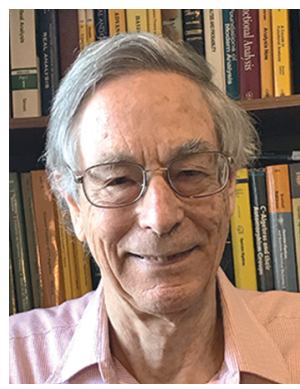

Marc Rieffel

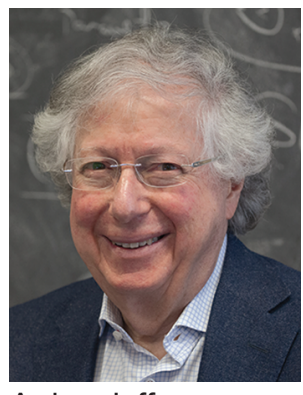

Arthur Jaffe

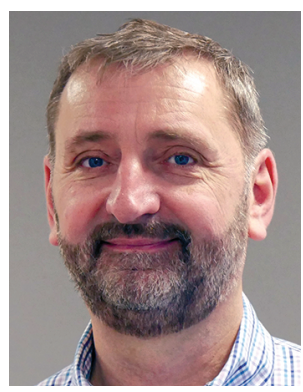

Mikael Rørdam

\section{Credits}

Figure 1 is courtesy of Bruce E. Blackadar. Figure 2 is courtesy of Piotr M. Hajac. Figure 3 is courtesy of Masamichi Takesaki. Figures 4, 5, and 7 are courtesy of Arthur Jaffe. Figure 6 is courtesy of Kenneth A. Ribet.

Figures 8, 9, and 11 are courtesy of Liming Ge. Figure 10 is courtesy of Mikael Rørdam. Author photos are courtesy of the authors. 